\title{
Análise da usabilidade no vestuário plus size
}

\section{Usability analysis in plus size apparel}

\author{
Mara Rubia Theis ${ }^{[1]}$, Vivian Andreatta Los $^{[2]}$, Mariana \\ Luísa Schaeffer Brilhante ${ }^{[3]}$, Lucimeri Sabin Ferreira ${ }^{[4]}$, \\ Valdecir Babinski Júnior ${ }^{[5]}$, Anna Karolyna Wolf ${ }^{[6]}$, \\ Nicolle Camilo Leite ${ }^{[7]}$
}

\begin{abstract}
Resumo: esse artigo objetivou validar aspectos ergonômicos e de usabilidade da modelagem do vestuário para o segmento de varejo plus size, por meio de um estudo de caso em Jaraguá do Sul (SC). Para a coleta de dados, realizou-se: (I) uma visita in loco na sede da empresa e na loja física; (II) um exame laboratorial de seis peças de vestuário. A análise de dados ocorreu de modo interpretativo, com vistas a confrontar os achados sob as seguintes categorias: (I) liberdade de movimento; (II) autonomia do usuário; e (III) vestibilidade. Para a validação das categorias foram convidadas duas modelos de prova que, após vestirem as peças, responderam a uma escala de diferencial semântico. A partir dos resultados pode-se concluir que: (I) a moda plus size está crescendo nas empresas da região; (II) até o número 50 as consumidoras são atendidas com excelência na região; e (III) as modelagens com folgas e o uso de tecidos com elastano favorecem a vestibilidade para esse público.
\end{abstract}

[1] Doutoranda em Design, UFSC.marubiat@ifsc.edu.br

[2] Mestra em Educação, FURB. vlos@ifsc.edu.br

[3] Mestranda em Design de Vestuário e Moda, UDESC. marsbxx@gmail.com

[4] Pós-graduada em Interdisciplinaridade na Prática

Pedagógica, FURB. lucimeri.sabin@hotmail.com

[5] Mestre em Design de Vestuário e Moda, UDESC.vj.babinski@gmail.com

[6] Estudante do Curso Técnico Integrado em Modelagem

do Vestuário, IFSC. annakarolwolf@gmail.com

[7] Estudante do Curso Técnico Integrado em Modelagem

do Vestuário, IFSC.nicollecamilo24@gmail.com 
Palavras-chave: modelagem do vestuário. Moda plus size. Usabilidade.

Abstract: this article aimed to validate ergonomic and usability aspects of clothing modeling for the plus size retail segment, through a case study in Jaraguá do Sul (SC). For data collection, there were: (I) an on-site visit at the company's headquarters and at the physical store; (II) a laboratory examination of six garments. Data analysis was performed in an interpretive way, with a view to confronting the findings under the following categories: (I) freedom of movement; (II) user autonomy; and (III) wearability. For the validation of the categories, two test models were invited that, after dressing the pieces, answered a semantic differential scale. Based on the results, it can be concluded that: (I) plus size fashion is growing in companies in the region; (II) up to number 50, consumers are served with excellence in the region; and (III) modeling with clearances and the use of fabrics with spandex favor wearability for this audience.

Keywords: clothing modeling. Plus size fashion. Usability.

\section{INTRODUÇÃO}

O termo plus size (tamanho grande, em livre tradução para o português) foi utilizado pela primeira vez em 1920 pela marca norte-americana Lane Bryant. Em seus anos iniciais, a marca - que foi fundada em 1904 - produzia peças de vestuário para mulheres grávidas em grande escala. Com o passar do tempo, as peças começaram a ser projetadas para vestir corpos maiores que o padrão, principalmente com vestidos longos e casacos. O sucesso comercial de Lane Bryant foi tanto que o termo plus size se popularizou e influenciou o surgimento de outras empresas focadas em manequins acima do tamanho 44 (REVISTA CLAUDIA, 2010).

Segundo Aires (2019), ainda no decorrer do século XX, o período entre as décadas de 1970 e 1990 foi marcado por um incremento na indústria da moda plus size, principalmente nos Estados Unidos da América. O autor ressalta que o cenário local colaborou para tal crescimento: o aumento do peso médio da cidadã estadunidense saltou dois tamanhos em relação ao manequim feminino médio até então.

No Brasil, de acordo com o Sebrae (2015, p. 2) ao debruçar-se sobre dados do Ministério da Saúde divulgados em 2014, cerca de "[...] 50,8\% dos brasileiros estão acima do peso, e destes, 17,5\% são obesos". Ainda, o Sebrae (2015, p. $1)$, relata “[...] crescimento anual de $6 \%$ no mercado de moda 
plus size, o que corresponde a cerca de $\mathrm{R} \$ 5$ bilhões do faturamento total do segmento de vestuário", segundo dados da Associação Brasileira do Vestuário (Abravest). Em 2019, o Brasil tinha $61,7 \%$ dos consumidores acima do peso, ou seja, mais da metade da população (IBGE, 2019). Aires (2019) assevera que esse grupo social se encontra desassistido mediante a oferta de peças de vestuário.

A problemática atual da moda plus size perpassa a ausência de padronização no dimensionamento das peças de vestuário pois, na literatura brasileira, não há um consenso sobre em qual numeração de roupa se inicia o plus size. Assim, devido à falta de padronização específica, a grade plus size inicia-se, dependendo do autor, a partir do tamanho 44 ou 46 (BETTI, 2014; MARCELJA, 2015). De acordo com Büttner (2019), acrescenta-se o fato de que cada marca oferece peças que podem ter modelagens inadequadas para as proporções corpóreas desse público. A autora sustenta que muitas mulheres acabam por adquirir as peças de vestuário que servem, mesmo que de maneira inadequada, e não as que de fato desejam.

Segundo a pesquisa de Duarte e Conceição (2021), apesar do crescimento e maior visibilidade da moda plus size, esse mercado ainda é deficitário e não satisfaz esses consumidores, nesse contexto, o varejo pode refletir a estigmatização desse público, que acredita ser mais fácil emagrecer para ser socialmente aceito, pois a experiência de consumo não se torna um processo divertido, tampouco agradável. Portanto, segundo os autores, torna-se necessário que as empresas e marcas que trabalham com a moda plus size analisem as principais reclamações e insatisfações desses consumidores, a fim de corrigi-las e atendê-las.

As mulheres plus size estão em busca de um produto que satisfaça sua necessidade pessoal, em termos de usabilidade e ergonomia, e contribua para a sua beleza. Contudo, segundo Amari (2014), a moda e as empresas de vestuário ainda não consideram o tamanho grande como padrão de tamanho normal, mas como tamanho "especial", sendo que 
os cortes, os tecidos, as estampas e as cores são pensados e produzidos quase que exclusivamente para pessoas magras. Todos aqueles que fogem desse conceito encontram certa dificuldade na hora de comprar peças de roupa com tendência de moda e modelagens adequadas (AMARI, 2014).

As consumidoras plus size ainda podem recorrer ao varejo on-line, que conta com mais opções, apesar de as tabelas de medidas das empresas não apresentarem tamanhos e opções adequadas ao público estudado nessa pesquisa. Büttner (2019, p. 100) realizou uma entrevista sobre como as consumidoras se sentem ao comprar da moda plus size e uma das entrevistadas afirmou que "[...] a falta de padronização da tabela de medidas causa empecilhos no seu comportamento de compra no varejo online". Assim, é visto que o varejo delimita o consumo desse público, reforçando a exclusão das consumidoras pelos formatos de seus corpos e também por não terem ofertas desejadas ou produtos tidos como sofisticados (ZANETTE; LOURENÇO; BRITO, 2013; WINTER; MORA$E S, 2013)$. Büttner (2019, p. 17) explicita que "Isso acontece porque a numeração das roupas encontradas é limitada, de modo que esse público consumidor torna-se um nicho atendido apenas por empresas especializadas".

Assim, conforme o exposto, pode-se pressupor que o mercado trabalha com descaso com o segmento plus size, pois não se preocupa em confeccionar roupas que considerem a usabilidade e a tendência de moda e de mercado a partir da modelagem do vestuário para as consumidoras. Logo, o presente artigo busca validar aspectos ergonômicos e de usabilidade da modelagem do vestuário para o segmento de varejo plus size, por meio de um estudo de caso em Jaraguá do Sul (SC).

Esse artigo define-se a partir de abordagem qualitativa e descritiva, com a análise da usabilidade de peças do vestuário para o público plus size feminino, a partir de um estudo de caso. A seguir, apresenta-se a fundamentação teórica dessa pesquisa. 


\section{PÚBLICO PLUS SIZE}

A história da moda plus size evoluiu junto com a construção dos padrões de beleza. No começo, a indumentária era destinada a vestir corpos gordos que, por sua vez, eram compreendidos enquanto sinônimo de beleza, fertilidade e abundância material. Até a Idade Média, o padrão de beleza foi sustentado com base em tamanhos amplos. Como exemplo, cita-se a prática comum entre a nobreza europeia de utilizar artifícios para fantasiar o volume de um ventre gestacional, o que era comum em meados de 1350 (GRUMBACH, 2009). Em voga desde o Renascimento, a cintura espartilhada tornou-se objeto de desejo feminino entre os séculos XV e XX. Em especial, no auge da Belle Époque, o ideal de beleza feminina passou a estar relacionado com a magreza e a fragilidade (BRAGA, 2007).

Já na segunda década do século XXI, a difusão da blogosfera sobre o assunto tornou a moda plus size popular entre as consumidoras jovens. Entre as formadoras de opinião, blogueiras e influenciadoras digitais no mercado, cita-se o exemplo de Renata Poskus. Criado em 2007, o blog Mulherão possuía cerca de 300.000 mil acessos mensais (REVISTA CLAUDIA, 2010). Ao comentar sobre o sucesso obtido por Renata Poskus Vaz, editora de uma revista de moda de importância nacional, aponta para os conteúdos que relacionam vivências e experiências da autora com o universo de suas leitoras. Com o sucesso do blog, a influenciadora criou, em 2010, o Fashion Weekend Plus Size (Final de Semana de Moda para Tamanhos Maiores, em livre tradução), que conta com duas edições anuais articuladas a desfiles de marcas autorais e palestras sobre autocuidados, aparência e autoestima.

Para Fischler (1989, p. 95), “[...] os gordos parecem violar constantemente as regras [sociais] que governam o comer, o prazer, o trabalho e o esforço, a vontade e o controle de si". Na cultura do século XXI, acostumada a rotular os indivíduos conforme sua aparência, torna-se insuficiente combater o sobrepeso, o ideal de beleza se baseia em ter corpo firme, 
musculoso e definido (LIPOVETSKY, 2000). Segundo Mattos, Zobolli e Mazzaboba (2012, p. 92-93), o corpo plus size é considerado gordo, sinônimo de "[...] flacidez, estrias e celulite costumam ser associados a falta de disciplina, preguiça e desleixo com o próprio corpo, quase um defeito moral". Porém, é necessário levar em consideração que as mídias sociais incutem na mente das pessoas esse ideal de beleza magro. Em tempos em que a beleza não é uma dádiva divina e sim uma conquista, as pessoas se tornam as únicas responsáveis pela sua aparência (SANT'ANNA, 2013). Para contribuir com a questão, Mattos, Zobolli e Mazzaboba (2012, p. 93) asseveram que "[...] a sociedade manipula e exerce poder sobre o corpo, sendo assim, a cultura atual transforma o próprio corpo em mercadoria a ser manipulada [...]". Ou seja, a própria mídia, o mercado de moda, consumo e as grandes marcas se acostumaram a tratar a pessoa com sobrepeso desta forma.

Uma matéria realizada pelo Jornal Metrópole, por Ilca Maria Estevão (2021, n.p) relatou que modelos como a Ashley Graham afirmam que odeiam ter que falar constantemente sobre o próprio corpo, a modelo diz que gostaria de ser vista apenas como "mulher", sem o rótulo plus size. Apesar de afirmar que se trata de um assunto pertinente e que o sobrepeso deve ser discutido para alcançar o bem-estar das pessoas, Ashley Graham afirma que ainda abordará o assunto com maior ênfase, visto que a sua representatividade baseia-se no fato de que " $68 \%$ das mulheres norte-americanas usam tamanho 14 (48 brasileiro) ou mais". Quanto ao mercado de vestuário, a maioria das marcas não está produzindo um tamanho que reflita o público plus size realmente. Com padrões de medidas e tabelas que não condizem com a realidade desse público-alvo, tanto o consumidor quanto a marca tornam-se prejudicados com a falta de diretrizes para o setor. Afinal, estudos devem evoluir neste segmento de moda com vista a oferecer produtos adequados, com ergonomia pensada para estas pessoas, levando em consideração a sua anatomia e articulações. 
Ao levar em consideração a beleza do corpo plus size e o seu espaço na sociedade, Duarte e Conceição (2021) reforçam a necessidade de empresas e marcas do vestuário analisarem as insatisfações dos seus consumidores quanto aos produtos que estão sendo oferecidos para a moda plus size, visto que, para viabilizar o aumento nas vendas, esse público deve se sentir inserido no mercado de moda.

Quanto ao exposto, Heinrich (2005, n.p) complementa que "[...] o sucesso de um produto de vestuário ocorrerá se além de todos esses fatores, forem associados também, os valores ergonômicos, contribuindo assim, para que o vestuário amplie e some aos conceitos de conforto e estética". Afinal, a Associação Brasileira de Ergonomia (ABERGO, 2000) afirma que a ergonomia objetiva modificar o sistema de trabalho para adequar a atividade nele existente às características, habilidades e limitações das pessoas, com vistas ao seu desempenho eficiente, confortável e seguro.

De acordo com lida (2005), as qualidades técnicas, ergonômicas e estéticas desejáveis dos produtos destinam-se a satisfazer determinadas necessidades humanas e, dessa forma, direta ou indiretamente entram em contato com o homem. Para que esses produtos tenham bom funcionamento em suas interações com os usuários ou consumidores, devem seguir características básicas como: (I) qualidade técnica - que é o que faz o produto funcionar; (II) qualidade ergonômica - que garante a interação do produto com o usuário e facilidade de manuseio; (III) adaptação antropométrica; (IV) fornecimento de informações; (V) compatibilidade de movimentos; (VI) conforto; e (VII) segurança. A qualidade estética também é fundamental, pois proporciona prazer ao consumidor.

Dessa forma, a segurança, o conforto e a usabilidade na moda plus size se dão por meio da ergonomia, que pensa em cada tamanho e de que forma o público se sentirá por meio de tal vestimenta. A seguir, discorre-se acerca da ergonomia e usabilidade no vestuário. 


\section{ERGONOMIA E USABILIDADE NO VESTUÁRIO}

A ergonomia foi desenvolvida a fim de satisfazer as necessidades do homem, durante a II Guerra Mundial (1939-1945), a partir do estudo da relação e da adaptação do trabalho ao homem. Em outras palavras, a ergonomia procura reduzir a fadiga, o estresse, os erros e os acidentes para proporcionar segurança, satisfação e saúde ao homem ao realizar determinado trabalho ou atividade (AMARI, 2014). De acordo com lida (2005), a ergonomia é o estudo da adaptação do trabalho ao homem, e envolve não apenas o espaço físico, mas, também, as questões organizacionais. Amplamente, estuda os critérios necessários para adaptar o ambiente e os produtos ao ser humano e, para isso, aplica teorias, princípios, dados e métodos que possam preservar a vida humana, nos aspectos relativos à saúde, segurança, conforto e satisfação (SILVEIRA, 2008).

A ergonomia é uma atitude profissional que se agrega à prática em uma profissão definida, assim, torna-se possível falar de um médico ergonomista, de um psicólogo ergonomista, de um designer ergonomista, entre outros. Para Saltzman (2004), essa relação com o conforto é dada justamente ao ver e entender esse espaço do corpo, a sua relação de distanciamento e proximidade com ele. 0 processo de modelagem está diretamente relacionado à matéria-prima em que se confeccionam as peças, para que cada tipo de tecido tenha um molde específico, atrelado aos beneficiamentos que se disporá de cada peça após sua confecção (SALTZMAN, 2004).

Assim, segundo Amari (2014), é visto que, ao projetar um produto do vestuário, não se deve limitar apenas a questões estéticas, apesar de ser um importante componente, mas deve-se levar em conta a ergonomia desde o início do projeto, pois é o fator que, essencialmente, garante a boa interação do produto com o usuário. Amari (2014) sustenta, também, que a modelagem aliada à ergonomia favorece os parâmetros de observação relativos aos movimentos do corpo, usabilidade, contornos corpóreos, estiramentos e relaxamentos da musculatura. Todos esses conhecimentos facilitam a pro- 
jeção de roupas com assertividade na modelagem, que se ajusta à capacidade de cada corpo. A modelagem disposta de ergonomia visa adequar o vestuário ao cumprimento do seu papel, delineia o conjunto anatômico em favor da vestibilidade adequada (AMARI, 2014). Nesse contexto, deve-se destacar que o vestuário não atende somente a anatomia, mas, atualmente, tornou-se um modo de expressão humana, onde o estilo se tornou uma identidade.

Conforme Silveira (2008, p. 34), a usabilidade "[...] significa facilidade e comodidade no uso dos produtos, tanto no ambiente doméstico como no profissional", além de, juntamente com os princípios da ergonomia aplicados ao vestuário, relacionar-se com a forma de vestir o corpo. A autora ainda afirma que o conhecimento da anatomia e o estudo das dimensões corporais servem de base para a fabricação dos produtos de vestuário, visto que a roupa atua como uma extensão do próprio corpo (SILVEIRA, 2008).

Quanto à boa vestibilidade das peças, Burgo (2004) afirma que essa deve estar relacionada aos seguintes aspectos: ao espaço que se estabelece entre o produto e o corpo; à silhueta configurada e à espessura do material utilizado; e às folgas do tecido em relação ao corpo do usuário. Além disso, classifica o grau de versatilidade numa escala de zero a quatro, que se refere à distância do produto, no caso a roupa, em relação ao corpo que está vestindo. Entende-se, então, que as modelagens devem ter folgas obedecidas, de acordo com cada tipo de tecido e a sua composição (BURGO, 2004).

Na fase da confecção do vestuário, a modelagem é uma etapa importante para um bom caimento e conforto da roupa (GRAVE, 2004). Nesse contexto, Aires (2019) corrobora ao afirmar que o vestuário se torna a moda, que basicamente não é apenas vestir, mas corresponde ao que ele deseja demonstrar por meio de sua aparência, além de estar diretamente relacionado à construção social, identidade e expressão pessoal; sendo que, ao mesmo tempo, as pessoas buscam ser únicas por meio do consumo (AIRES, 2019). 
Manfio e Souza (2018, n.p), ao estudarem a obra de Burgo (2004), entendem que o "[...] domínio de conhecimentos a respeito das possibilidades e estratégias construtivas aprimora a eficácia da produção, fator este que, seja em âmbito acadêmico ou industrial, auxilia na materialização quanto à forma e silhuetas idealizadas [dos produtos de vestuário]".

Amari (2014) relata que, com o aumento do peso das pessoas no mundo todo, a sociedade atual encara uma grande diferença entre o ideal de beleza e a realidade da maioria da população. A cultura da magreza coloca o sobrepeso visto como algo ruim, apesar de representar mais da metade da população brasileira adulta. De acordo com a pesquisa do IBGE (2019), 61,7\% dos brasileiros estariam acima do peso.

Marcelja (2015, p. 11) explicita que, "Todavia, é perceptível que a obesidade incomoda a sociedade, e estar acima do peso passou a ser visto como desleixo e falta de cuidado". Nesse contexto, torna-se subjetivo o fato de que o mercado plus size comercializa roupas discretas que buscam disfarçar os "defeitos" da mulher, pois, segundo as consumidoras que usam produtos de moda nos tamanhos acima do 44, é recorrente ouvir a reclamação de que muitas lojas vendem roupas plus size com cara de senhora ou sem estilo (AMARI, 2014). Sousa Júnior (2018) relata que é perceptível o estigma social e as dificuldades de encontrar roupas em tamanhos maiores como reflexos dos problemas sociais e de dificuldades de oferta no mercado de moda plus size em todo o mundo.

\section{PROCEDIMENTOS METODOLÓGICOS}

Esse artigo parte de uma abordagem qualitativa, pois tem como base aspectos da realidade que não podem ser quantificados, fundamentando-se na compreensão e interpretação de relações socias (GERHARDT; SILVEIRA, 2009). Então, analisa-se a usabilidade de peças do vestuário para o público plus size feminino, a partir de um estudo de caso. Pode-se dizer que o caráter dessa pesquisa é descritivo, visto que “[...] descreve características de determinada população 
ou fenômeno ou o estabelecimento de relações entre variáveis" (GIL, 2007, p. 28).

Inicialmente, esse artigo foi construído com base em amplas referências bibliográficas, que objetivam tomar conhecimento de conteúdos já publicados sobre o assunto. Complementa-se a partir da entrevista com uma modelo plus size, que teve experiências práticas do problema, Grasy Mara Rosa, também proprietária de uma loja plus size em Jaraguá do Sul (SC) - Grasy Rosa Boutique Plus Size - com objetivo de registrar relatos de suas dificuldades, anseios e situações presenciadas durante a formação de sua empresa. Esses relatos trouxeram aprofundamento na pesquisa sobre o assunto, por meio da realidade do mercado, onde verificaram-se as necessidades das consumidoras, além de sua opinião sobre a valorização de seus corpos por meio das roupas ofertadas pelo departamento.

O estudo de caso foi realizado na Grasy Rosa Boutique Plus Size, que inicialmente era uma loja física, mas, com complicações financeiras ocasionadas pela pandemia do Covid-19, se tornou loja on-line. Foram visitadas a sede da empresa e, também, outra loja, que se trata de uma loja física, a Formitz Store em Guaramirim (SC), que oferta a moda "magra" feminina e masculina, a feminina juvenil e a plus size feminina. Foram escolhidas três peças plus size para a análise - uma top, uma bottom, e uma one piece -, aprofundando-se na modelagem das roupas. Analisou-se as questões de usabilidade - (I) liberdade de movimento, (II) autonomia do usuário e (III) vestibilidade. Para validação das categorias foi aplicada uma escala de diferencial semântico, com base nos preceitos teóricos de Osgood, Suci e Tannenbaum (1957) que, por sua vez, orientam a escolha de pares antagônicos como descritores opostos para mensuração de conceitos relacionados à percepção humana. Nesse sentido, elaborou-se o Quadro 1, a seguir. 


\begin{tabular}{|c|c|c|c|c|c|c|c|}
\hline Categoria & Descritores & 2 & 1 & $\mathbf{0}$ & 1 & 2 & Descritores \\
\hline \multirow{2}{*}{$\begin{array}{l}\text { Liberdade de } \\
\text { movimento }\end{array}$} & Fácil de andar e sentar & & & & & & Difícil de andar e sentar \\
\hline & $\begin{array}{l}\text { Permite os movimentos } \\
\text { naturais }\end{array}$ & & & & & & $\begin{array}{l}\text { Prende os movimentos } \\
\text { naturais }\end{array}$ \\
\hline \multirow[t]{2}{*}{$\begin{array}{l}\text { Autonomia } \\
\text { do usuário }\end{array}$} & $\begin{array}{l}\text { Permite se vestir } \\
\text { sozinho(a) }\end{array}$ & & & & & & $\begin{array}{l}\text { Não permite se } \\
\text { vestir sozinho(a) }\end{array}$ \\
\hline & Segurança & & & & & & Insegurança \\
\hline \multirow[t]{2}{*}{ Vestibilidade } & Fácil de vestir & & & & & & Difícil de vestir \\
\hline & Fácil de desvestir & & & & & & Difícil de desvestir \\
\hline
\end{tabular}

Fonte: elaborado pelos autores (2021).

Estabelecida a escala (Quadro 1), a modelo foi orientada a vestir as peças de roupas selecionadas e responder o quadro logo após vestir as peças. Para cada peça, optou-se por uma cor para o preenchimento das colunas. Os resultados foram analisados e podem ser observados a seguir.

\section{RESULTADOS E DISCUSSÕES}

\subsection{GRASY ROSA BOUTIQUE PLUS SIZE}

Fundada em 17 abril de 2019, a loja Grasy Rosa Boutique Plus Size criada pela modelo plus size Grasy Mara Rosa, teve o intuito de reforçar a autoestima de um dos públicos que ainda permanecem negligenciados na moda - como relatam Amari (2014), Aires (2019) e Duarte e Conceição (2021) —: as consumidoras plus size. A proprietária conta que levou 27 anos para aceitar-se e entender que pode ser bonita independen- 
temente do número que usa, mensagem que deseja transmitir para as mulheres. Busca incentivar as consumidoras a fugir do que é padrão e mostrar que podem encontrar no mercado roupas belas e elegantes para seu biótipo.

As roupas da loja contam com peças diversificadas, sendo a maioria delas exclusiva. A própria Grasy é quem seleciona as peças, buscando $90 \%$ em shoppings atacadistas e $10 \%$ em lojas de São Paulo, e mantém um acervo aproximado de 300 peças nos tamanhos a partir do 44 até o 56 . A empresária conhece a moda plus size e busca escolher marcas de destaque do segmento para abastecer a boutique. As marcas mais procuradas são: Blubetty, Carmela, Charlot, Inove e Comprometida. Em abril de 2021, Grasy teve que transformar sua loja física em on-line e com atendimento personalizado, para atender a todos sem dificuldades, devido às complicações ocasionadas pelo cenário pandêmico instaurado pela Covid-19.

Para análise de caso foram escolhidas três peças na loja pesquisada: uma blusa de manga comprida de tecido plano, uma saia de couro ecológico e um vestido de malha. Abaixo segue, respectivamente, a blusa, saia e vestido escolhidos.



A própria Grasy provou as peças, chegando na conclusão registrada no Quadro 2, na escala semântica abaixo.
Figura 1: Roupas para o público plus size da loja Grasy Rosa Boutique Plus Size Fonte: Grasy Rosa Boutique Plus Size (2021). 
Quadro 2: Escala de diferencial semântico aplicada nas peças da Loja Grasy Rosa Boutique Plus Size

\begin{tabular}{|c|c|c|c|c|c|c|c|}
\hline Categoria & Descritores & 2 & 1 & $\mathbf{0}$ & 1 & 2 & Descritores \\
\hline \multirow[t]{2}{*}{$\begin{array}{l}\text { Liberdade de } \\
\text { movimento }\end{array}$} & Fácil de andar e sentar & $\begin{array}{l}x \\
x\end{array}$ & & $\mathrm{x}$ & & & Difícil de andar e sentar \\
\hline & $\begin{array}{l}\text { Permite os movimentos } \\
\text { naturais }\end{array}$ & $\begin{array}{l}\mathrm{x} \\
\mathrm{x}\end{array}$ & & $\mathrm{x}$ & & & $\begin{array}{l}\text { Prende os movimentos } \\
\text { naturais }\end{array}$ \\
\hline \multirow[t]{2}{*}{$\begin{array}{l}\text { Autonomia } \\
\text { do usuário }\end{array}$} & $\begin{array}{l}\text { Permite se vestir } \\
\text { sozinho(a) }\end{array}$ & $\begin{array}{l}\mathrm{x} \\
\mathrm{x} \\
\mathrm{x}\end{array}$ & & & & & $\begin{array}{l}\text { Não permite se } \\
\text { vestir sozinho(a) }\end{array}$ \\
\hline & Segurança & $\mathrm{x}$ & $\begin{array}{l}\mathrm{x} \\
\mathrm{x}\end{array}$ & & & & Insegurança \\
\hline \multirow[t]{2}{*}{ Vestibilidade } & Fácil de vestir & $\begin{array}{l}X \\
x\end{array}$ & $\mathrm{x}$ & & & & Difícil de vestir \\
\hline & Fácil de desvestir & $\begin{array}{l}X \\
x\end{array}$ & $\mathrm{x}$ & & & & Difícil de desvestir \\
\hline
\end{tabular}

Fonte: elaborado pelas autoras (2021) Blusa: 0 - Saia: 0 -Vestido: 0

De acordo com a análise, concluiu-se que a loja Grasy Rosa Boutique Plus Size oferta roupas construídas com base nas tendências da moda, com modelagens ajustadas a fim de mostrar o corpo plus size. Duarte e Conceição (2021) sinalizam que o corpo plus size deve ser valorizado como um público-alvo a ser atingido e um grande nicho de mercado, que aumenta a cada ano. Não sendo necessário abster esse público e muito menos esconder as formas desses corpos, afinal, cada corpo tem a sua beleza. 
Quanto aos preços praticados por estas marcas que valorizam o corpo plus size, entende-se que, geralmente, são mais elevados se comparados à média no mercado atual, sendo compatível com o padrão de marcas com maior valor agregado, como é o caso da loja Grasy Rosa Boutique Plus Size. Apesar de prezar pelo conforto, utiliza tecidos diferenciados, visto que esse fator influencia na usabilidade das peças. Nota-se que as peças escolhidas para a pesquisa de usabilidade possuem tecidos agradáveis, como o tecido usado no vestido. Já os tecidos como o couro ecológico naturalmente oferecem menor capacidade de movimento da consumidora. lida (2005) e Silveira (2008) estudam os critérios necessários para adaptar os produtos ao ser humano, ou seja, criar levando em conta as necessidades do público alvo torna-se indispensável.

A saia de couro ecológico, por ser bem justa, não foi bem avaliada nos quesitos de liberdade de movimento, já quanto à questão da autonomia do usuário, apesar de possibilitar vestir-se sozinho, sua modelagem tornou a avaliação mediana no quesito vestibilidade. Manfio e Souza $(2018$, p. 3) sinalizam que as regras de folgas na modelagem são "[...] auxiliadores no processo construtivo, interferindo para um efetivo conforto e adequação da peça ao usuário, além de correta configuração das silhuetas projetadas". Ou seja, peças com modelagens muito justas desfavorecem a boa vestibilidade do vestuário, quando esses tecidos não apresentam elastano. A blusa com modelagem ombro a ombro se mostrou extremamente confortável pelos elásticos que se moldam ao corpo, mangas folgadas que permitem a movimentação livre dos braços e atingiu a maior avaliação em todos os quesitos. $O$ vestido teve excelentes avaliações, por ser um tecido de maIha que se molda ao corpo. Sua modelagem se mostra ousada, com a abertura em forma de triângulo, e por ser relativamente curto, o quesito segurança também foi avaliado como mediano. Silveira (2008) reforça que, para uma peça de roupa ser de fácil usabilidade, ela precisa ser fácil de vestir, fácil de se movimentar e usar, tendo a comodidade o principal requisito. 


\subsection{FORMITZ STORE}

Fundado em 1986, o Grupo Formitz é situado em Guaramirim (SC) e conta, atualmente, com dois parques fabris que englobam processos desde a tecelagem até a confecção das peças. Com dedicação e excelência, produz moda com responsabilidade, explora tendências e inova para agradar o consumidor. Dispõe de quatro divisões dentro da marca Formitz: (I) Formitz Fashion, para mulheres dentro do padrão industrial, com tamanhos do P ao GG; (II) Formitz Curves, para mulheres acima do peso, com tamanhos do $P$ ao GG, atendendo do número 40 até o 50; (III) Formitz Plus Size, também para mulheres plus size, com tamanhos o 52 ao 58; (IV) a Formitz masculino, para homens, com tamanhos do P ao EG; e, ainda, (V) a marca Dink Do, moda juvenil feminina, com tamanhos do PP ao G. A empresa vende tanto peças em atacado quanto varejo para consumidores em sua loja. A loja física, localizada ao lado de uma das fábricas, oferta variadas roupas, tamanhos e estilos para cada público. Por conta da pandemia ocasionada pela Covid-19, se adaptou também para atendimento on-line.

$\mathrm{Na}$ análise de caso, foram escolhidas três peças: um conjunto de blusa e saia e um vestido longo, todos de tecido plano e da coleção tropical inverno 2021 da empresa. Abaixo segue, respectivamente, o conjunto e o vestido.

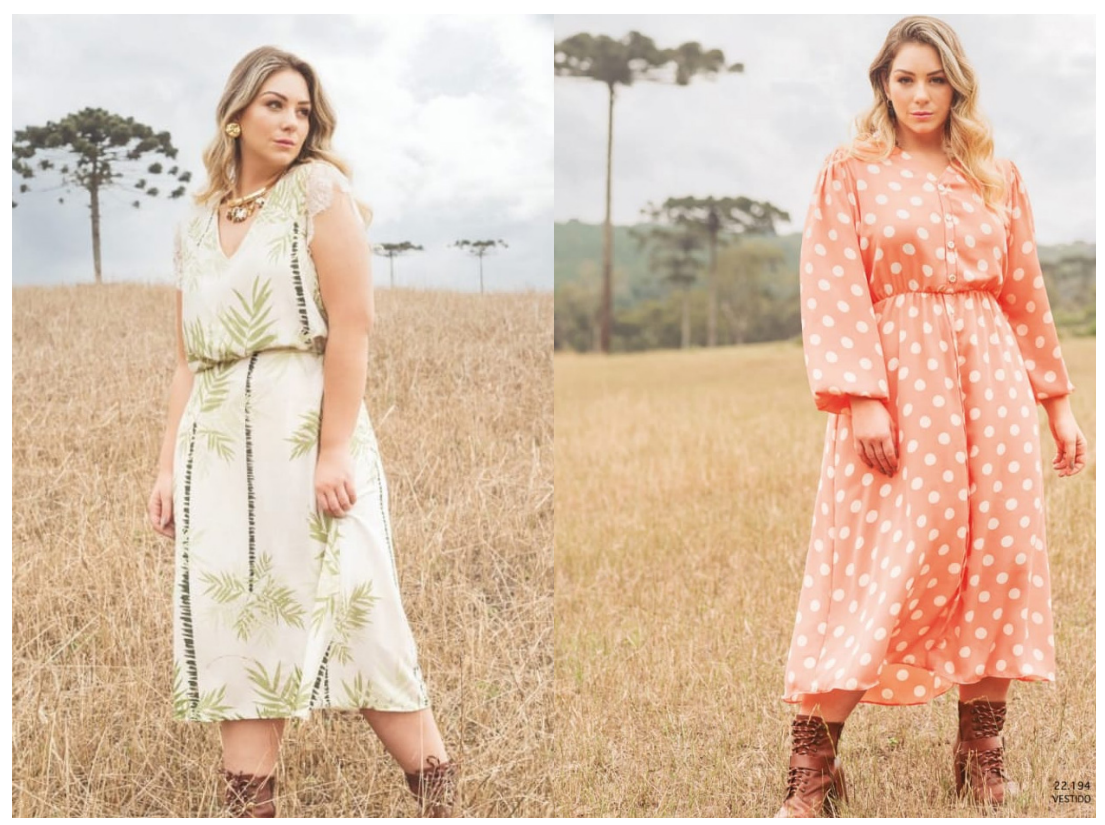

Figura 2: Roupas para o público plus size da marca Formitz Fonte: Formitz (2021). 
A modelo provou as peças e chegou à conclusão registra-

da no Quadro 3, na escala semântica abaixo.

Quadro 3: Escala de diferencial semântico aplicada nas peças da marca Formitz

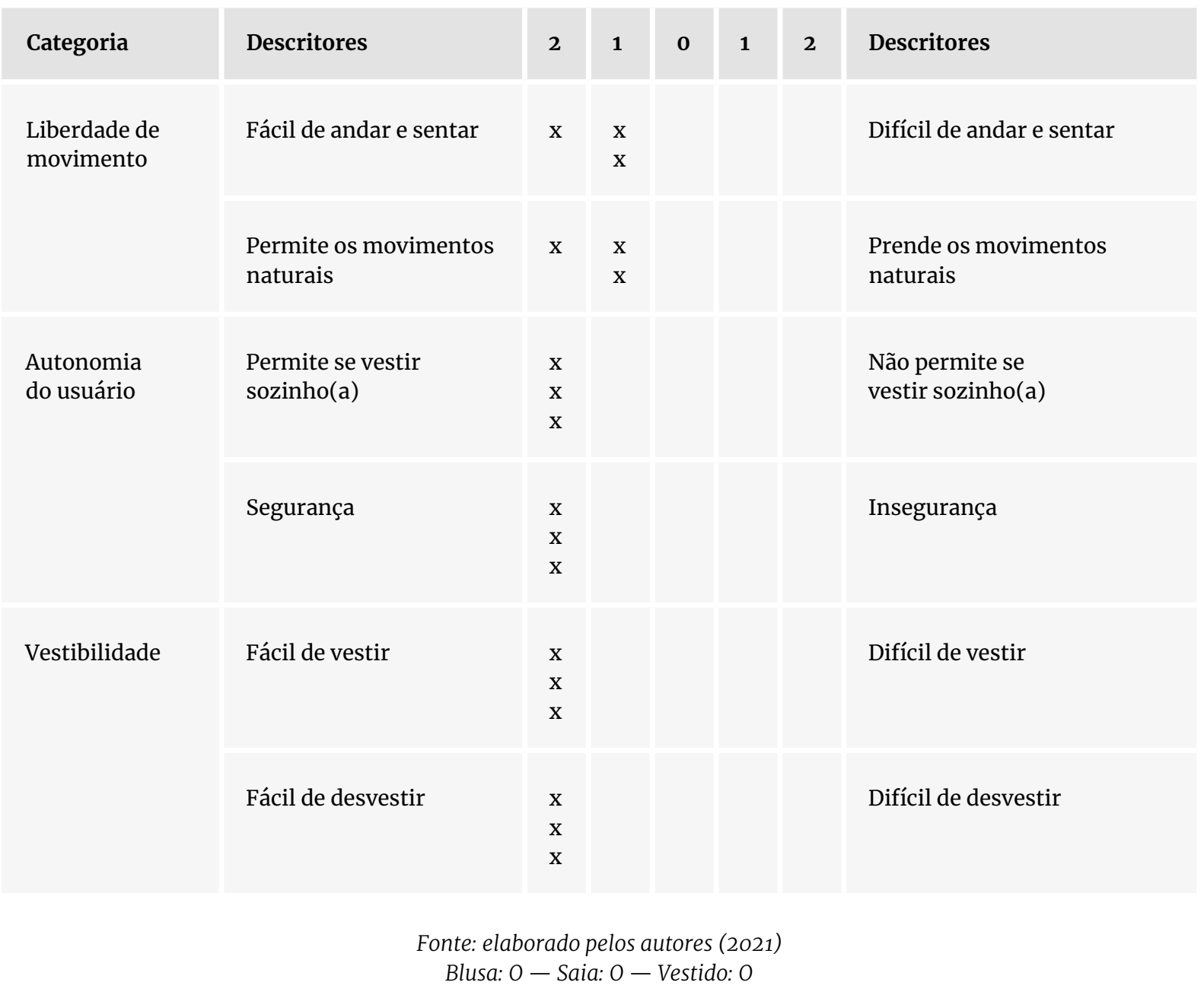

No estudo de caso dessa marca, evidenciou-se que suas peças foram construídas com base nas tendências da moda e oferecem vários estilos, o que impressionou as pesquisadoras, visto a carência de oferta de roupas que agradem o público plus size na mesma intensidade, qualidade e versatilidade que se oferece nas roupas para a moda "magra" de suas coleções. 
A blusa - com modelagem levemente justa - se mostrou extremamente confortável e com um bom caimento, ao mesmo tempo que valorizou o corpo plus size. Apesar de o tecido ser plano, a peça vestiu com folga e permitiu a movimentação livre dos braços, o que vai ao encontro com a abordagem de Manfio e Souza (2018) e Silveira (2008), que valorizam modelagens com folgas, que possibilitem os movimentos e em tecidos confortáveis. Essa mesma blusa, por ser fácil de vestir e usar, além de ter mangas curtas, teve a maior avaliação em todos os quesitos. A saia até o joelho, com modelagem larga, se mostrou confortável, porém por ser feita com tecido plano, não oferece $100 \%$ de liberdade de movimento, visto que não possui elastano, entretanto a autonomia do usuário e a vestibilidade se mostraram excelentes, por conta da folga na modelagem que, conforme Manfio e Souza (2018) e Burgo (2004), deixa o público seguro ao usar a peça. As folgas na modelagem do vestuário oferecem liberdade de movimento ao usuário de acordo com o estabelecido por Burgo (2004). O vestido, com modelagem larga, também se mostrou bem confortável e teve a mesma avaliação da saia, também por conta do tecido.

\section{CONSIDERAÇÕES FINAIS}

Entende-se que o objetivo almejado foi alcançado, visto que se realizou um estudo de caso em Jaraguá do Sul (SC) e na cidade ao lado, Guaramirim (SC) a fim de validar aspectos ergonômicos e de usabilidade da modelagem do vestuário feminino plus size. Notou-se que o vestuário produzido pela Formitz de Guaramirim (SC) apresenta modelagens com maior liberdade de movimento, que proporcionam autonomia do usuário e contribuem para a vestibilidade. Já as peças vendidas pela loja Grasy Rosa Boutique Plus Size apresentam, em sua maioria, modelagens justas e curtas e, geralmente, com tecidos sem elastano, que não favorecem a liberdade de movimento, tornando-se difícil de vestir. Segundo o exposto, conclui-se que apesar do evidente preconceito que esse público sofre, o presente artigo demonstra que nem todas as lojas negligenciam o consumidor plus size. 
A Formitz Store oferta a moda plus size até o número 50 e, se comparado à moda padrão industrial, em questão de tendências, qualidade, variedade e preços, se diferencia pouco da moda tradicional, sendo apenas em quantidade. Percebeu-se, porém, que sua coleção do número 52 até o 58 ainda não tem tanto espaço dentro da loja. De acordo com a análise, conclui-se que a loja Formitz Store busca ofertar tendências da moda por meio de peças com modelagens variadas e preços atraentes. A loja específica para o público plus size, chamada Grasy Rosa Boutique Plus Size, de Jaraguá do Sul (SC), apesar de ofertar muitas tendências e procurar valorizar o corpo, oferece roupas com preços acima da média, sendo perceptível que prefere oferecer roupas de marcas famosas — e dentro das tendências de moda - para públicos que não se importam em pagar mais por uma peça de roupa estilosa.

É evidente que, por ser de confecção própria, a Formitz encontra maior facilidade para atender os consumidores plus size, mesmo que numa numeração limitada, se comparado às lojas que compram em atacado de empresas de vestuário. Porém, tanto as empresas que fabricam quanto as lojas que revendem a moda plus size devem ser valorizadas, pois demonstram o crescimento da moda para esse público na cidade de Jaraguá do Sul (SC) e regiões próximas. Sugere-se que, em alguns anos, o mercado varejista e de moda cresça nesse segmento, com maior investimento na oferta de produtos para a linha plus size. Infere-se, ainda, que surgiram problemas ou imprevistos durante a pesquisa, pois a pandemia ocasionada Covid-19 não possibilitou um contato muito próximo das modelos (mulheres que vestiram as roupas).

Esse artigo demonstra que há esperança no crescimento desse segmento. Nota-se, também, que as empresas podem buscar esse público como público-alvo de suas coleções, como demonstram Duarte e Conceição (2021). Os consumidores de moda plus size pedem e esperam por mais lojas e/ ou marcas que atendam com cada vez mais numerações. 


\section{REFERÊNCIAS}

\section{ABERGO. A certificação do ergonomista brasileiro}

- Editorial do Boletim, Associação Brasileira de

Ergonomia, 2000. Disponível em: https://www.

abergo.org.br/. Acesso em: 20 jul. 2021.

AIRES, A. De Gorda A Plus Size: A Moda Do

Tamanho Grande. 1. ed. [S. I.]: Estação das

Letras e Cores Editora, 2019. 193 p.

AMARI, G. K. Valorização do corpo plus size através do

vestuário. 2014. 166 f. Trabalho de Conclusão de Curso

(Graduação) - Universidade Tecnológica Federal do

Paraná, Apucarana, 2014. Disponível: http://repositorio.

utfpr.edu.br/jspui/handle/1/5763. Acesso em: 29 jun. 2021.

BETTI, M. U. Beleza sem medidas? Corpo, gênero

e consumo no mercado de moda plus-size. 2014.

Dissertação (Mestre em Antropologia Social) -

Faculdade de Filosofia, Letras e Ciências Humanas,

Universidade de São Paulo, São Paulo, 2014.

BRAGA, J. História da Moda: Uma

Narrativa. Anhembi Morumbi, 2007.

BURGO, F. Il modellismo: tecnica del

modello sartoriale e industriale donna-uomo-

bambino. Milano: Editore Milano, 2004.

BÜTTNER, A. J. Bem-estar no consumo de moda Plus

Size. 2019. [180 f.]. Dissertação (Programa de Mestrado

Profissional em Comportamento do Consumidor) - Escola

Superior de Propaganda e Marketing, [São Paulo].

DUARTE, N. M.; CONCEIÇÃO, E. C. Plus Size Existe? Uma

Análise Da Experiência De Consumo De Indivíduos

Desconsiderados Pelo Mercado De Moda. R. Gest. Anál.,

Fortaleza, v. 10, n. 1, p. 123-142, jan./abr. 2021. Disponível

em: https://periodicos.unichristus.edu.br/gestao/article/

download/3448/1312. Acesso em: 22 jun. 2021. 
ESTEVÃO, I. M. Ashley Graham explica por que não quer mais ser chamada de plus size. Metrópole, 2021. Disponível em: https://www.metropoles.com/colunas/ilca-mariaestevao/ashley-graham-explica-por-que-nao-quer-maisser-chamada-de-plus-size. Acesso em: 8 mar. 2021.

FISCHLER, C. Obeso benigno, obeso maligno. In: SANT'ANNA, D. B. Políticas do Corpo: elementos para uma história das práticas corporais. São Paulo. Estação Liberdade. 1989.

FORMITZ. Catálogo de coleção 2021. Disponível em: https://www.formitz.com.br/. Acesso em: 20 jul. 2021.

GERHARDT, T. E.; SILVEIRA, D. T. Métodos de

pesquisa. Porto Alegre: Editora da UFRGS, 2009.

GIL, A. C. Métodos de pesquisa social.

6. ed. São Paulo: Atlas, 2007.

GRAVE, M. de F. A modelagem sob a ótica da

ergonomia. São Paulo: Zennex Publishing, 2004.

GRUMBACH, D. Histórias da moda.

$1^{\circ}$ edição. Cosacnaify, 2009.

HEINRICH, D. P. Modelagem e técnicas de interpretação para confecção industrial. $2^{\mathrm{a}}$

Edição. Novo Hamburgo, Feevale, 2005.

IBGE. Um em cada quatro adultos do país estava obeso em 2019: Atenção Primária foi bem avaliada. Disponível em: https://agenciadenoticias.ibge. gov.br/agencia-noticias/2012-agencia-de-noticias/ noticias/29204-um-em-cada-quatro-adultos-do-paisestava-obeso-em-2019. Acesso em: 8 mar. 2021.

IIDA, I. Ergonomia: projeto e produto. São

Paulo: Edgard Blucher Ltda, 2005. 
LIPOVETSKY, G. Sedução, publicidade e pós-modernidade.

Revista FAMECOS. Porto Alegre, $n^{\circ} 12$, junho 2000, periodicidade semestral. Disponível em: https:// revistaseletronicas.pucrs.br/index.php/revistafamecos/ article/download/3062/2340. Acesso em: 8 mar. 2021.

MANFIO, A. P.; SOUZA, P. de M. Determinantes da variação da vestibilidade na configuração dos produtos. Universidade Estadual de Londrina/Departamento de Design/CECA. 2018. EAIC - $27^{\circ}$ Encontro Anual de Iniciação Científica. Disponível em: http://www.uel.br/eventos/eaic/ anais/2018/artigo.php?cod=595. Acesso em: 8 mar. 2021.

MARCELJA, K. G. A busca por uma identidade através da moda plus size. COMUNICON - Congresso Internacional de Comunicação e Consumo. ESPM, São Paulo, 2015. Disponível em: http://anais-comunicon2015.espm.br/GTs/GT2/6_GT02_ Karen_Grujicic_Marcelja.pdf. Acesso em: 19 jun. 2021.

MATTOS, K. dos S.; ZOBOLI, F.; MEZZABOBA, C. O Corpo Obeso: Um corpo Deficiente? Considerações a partir da Mídia. 2012. In: Inclusão escolar da pessoa com deficiência: Utopia. Aracaju: Editora Criação. 230p. Disponível em: http://labomidia.ufsc.br/index. php/acesso-aberto/publicacoes/doc_download/452o-corpo-obeso. Acesso em: 15 maio 2021.

OSGOOD, C. E.; SUCI, G. J.; TANNENBAUM, $\mathrm{P}$. $\mathrm{H}$. The measurement of meaning. University of Illinois: Urbana, 1957.

SALTZMAN, A. El cuerpo diseñado: sobre la forma en el proyecto de la vestimenta. Buenos Aires: Paidós, 2004.

SANT'ANNA, M. C. dos P. Uma abordagem para a moda plus size no mercado de luxo. Instituto Europeu de Design. IED. São Paulo, 2013. Disponível em: https://ied.edu.br/biblioteca/saopaulo/01_01_13278.pdf. Acesso em: 15 maio 2021. 
SEBRAE. Nichos de mercado: moda plus size. 2015.

Disponível em: https://respostas.sebrae.com.br/nichosde-mercado-moda-plus-size/. Acesso em: 7 jul. 2021.

SILVEIRA, I. Usabilidade do vestuário: fatores técnicos/funcionais. Modaplavra e Periódico, Florianópolis, Ano 1, n.1, p. 2139, jan./jul. 2008.

SOUSA JÚNIOR, J. H. de. Avaliação de Consumidores Gordos e Magros em Relação aos Estímulos Promocionais de Moda Plus Size no Varejo de Vestuário. Dissertação de mestrado em administração. 145f. UFPE, Recife, 2018.

\section{REVISTA CLAUDIA. Criadora do blog Mulherão tem} autoestima tamanho GG. 2010. Revista Claudia, editora Abril. Disponível em: https://claudia.abril. com.br/sua-vida/criadora-do-blog-mulherao-temautoestima-tamanho-gg/. Acesso em: 10 nov. 2021.

WINTER, M. F. F.; MORAES, S. G. Nem 38, nem 42: Vaidade, Autoestima e autoconceito para a consumidora de moda plus size. II Seminário de Iniciação Científica, ESPM, São Paulo, out. 2013.

ZANETTE, M. C.; LOURENÇO, C. E.; BRITO, E. P. Z. O peso do varejo, o peso no varejo e a identidade: uma análise de consumidoras plus size. Revista de Administração de Empresas, São Paulo, FGV, v. 53, n. 6, p. 539-550, 2013. 